\title{
Two Types of Immature Erythrocytic Series in the Human Fetal Liver
}

\author{
Iwao Emura, Masao SEKIYA and Yoshihisa OHNISHI \\ Department of Pathology (Prof. OHnishi), Niigata University School of Medicine, Niigata, Japan
}

Received February 2, 1983

Summary. Cells of erythrocytic series in the human liver obtained from 109 embryos 28 to 49 days after ovulation and 76 fetuses between 8 to 22 weeks of gestation were investigated by light and electron microscopy. Antisera against fetal hemoglobin $(\mathrm{Hb}-\mathrm{F})$ were used in the immuno-peroxidase method to identify erythroblasts in the embryonic and fetal liver.

Immunoperoxidase staining for $\mathrm{Hb}-\mathrm{F}$ revealed that most of the hemopoietic cells found in fetal hepatic parenchy ma were erythrocytic in nature. The cells of the ery throcyte series consisted of large immature cells which were usually invaginating into the cytoplasm of hepatocytes, and small mature erythroblasts which tended to gather in the subendothelial spaces of the sinusoids.

The early hepatic erythroid progenitor cells observed in the intercellular spaces of the hepatocytes until 10 weeks of gestation (the early stage of hepatic hemopoiesis) distinctly differed in ultrastructure from the late hepatic erythroid progenitor cells which appeared after 10 weeks of gestation (the late stage of hepatic hemopoiesis).

These findings indicate that the progenitor cells of the erythrocytic series and the hemopoietic stem cells in the early stage of hepatic hemopoiesis are morphologically different from those in the late stage, and that the cells of erythrocytic series in the liver in the early stage differ in the course of maturation from those in the late stage.

Recent experimental investigation into colony forming units verified the existence of pluripotential hemopoietic stem cells (CFU-S) in laboratory animals (TILL and McCulloch, 1961; Becker, McCulloch and Till, 1963) and pluripotential hemopoietic progenitors (CFU-mix) in human bone marrow (FAUSER and MESSner, 1978, 1979). The ultrastructure of CFU-S is considered to resemble that of small lymphocytes (Bekкum et al., 1971; Dicke, Noord and Bekкum, 1973).

In our previous papers, we reported that the hemopoietic stem cells and the progenitor cells of megakaryocyte and granulocyte lineages in the liver in the late stage of hepatic hemopoiesis differed in ultrastructure from those in the early stage, and that the maturation courses of the former series were different from that of the latter series (Emura, Sekiya and Ohnishi, 1983a, b). Should the stem or precursor cells of the erythrocytic series in the early stage be morphologically different from those in the late stage, our assertion will be further supported.

In this context, the present study was conducted to reveal the ultrastructures of the cells of the erythrocytic series in the human embryonic liver. 


\section{MATERIALS AND METHODS}

The hepatic tissues examined were from 109 human embryos 28 to 49 days after ovulation and 76 human fetuses at 8 to 22 weeks of gestation, all being obtained by legal abortion from healthy woman.

Light microscopy: Eighteen embryos between 4 to $24 \mathrm{~mm}$ crown rump (C. R.) length (estimated age: 30 to 49 days after ovulation) and hepatic tissue of 34 fetuses (50 to 154 days of gestation) were fixed in $10 \%$ neutral formalin and then embedded in paraffin. Every fifth serial section was stained with hematoxylin-eosin, and the rest were subjected to silver impregnation, naphthol AS-D choloroacetate esterase and periodic acidSchiff reaction.

Transmission electron microscopy: Ninety-one embryos, including a 21 somite embryo of $3 \mathrm{~mm} \mathrm{C}$. R. length (estimated age: $27 \pm 1$ days), and the hepatic tissues of 76 fetuses were fixed as soon as possible after legal abortion in the fixative, which consisted of $2 \%$ glutaraldehyde in $0.1 \mathrm{M}$ phosphate buffer solution, $\mathrm{pH} 7.5$, at $4^{\circ} \mathrm{C}$ for $2 \mathrm{hrs}$. In the fixation, the embryos and livers were divided into small pieces using a dissection microscope. The tissue pieces were then rinsed in $0.1 \mathrm{M}$ phosphate buffer solution, $\mathrm{pH}$ 7.5 , and postfixed in $1 \%$ osmium tetroxide at $4^{\circ} \mathrm{C}$ for $2 \mathrm{hrs}$. All the specimens were dehydrated and embedded in Epon. Ten sets of 30-40 serial ultrathin sections were routinely prepared at an interval of $15-20 \mu \mathrm{m}$ from a block of each case. Ultrathin sections were counterstained with uranyl acetate and lead citrate. The sections were examined with a Hitachi HS-9 electron microscopy.

Immunohistochemical method: An indirect method was used. Briefly, the livers were fixed in $10 \%$ formalin and embedded in paraffin, and sections were dewaxed and treated with $0.3 \%$ hydrogen peroxide to block endogenous peroxidase. After exposure to non-immune goat serum, the sections were treated with the first antibody (rabbit antiserum to human $\mathrm{Hb}-\mathrm{F}$, Hoechst) at an optimal dilution (1:80) for $12 \mathrm{hrs}$ at $4^{\circ} \mathrm{C}$, and then washed and exposed to goat anti-rabbit IgG peroxide conjugated. All the sections were treated with diaminobenzidine in hydrogen peroxide and slightly counterstained with hematoxylin. Appropriate controls were included.

\section{RESULTS}

\section{Light microscopic observation of hepatic hemopoiesis}

Within the first month of gestation, no hemopoietic cells were found in the hepatic parenchyma, and all blood cells in the sinusoides were primitive erythroblasts of yolk sac origin.

A small number of isolated hemopoietic cells were first identified in the intercellular spaces among the hepatocytes of an embryo of $6.2 \mathrm{~mm} \mathrm{C}$. R. length (estimated ovulation age: 33 days). Along with the embryo's development, the cells of the erythrocytic series increased in number in the hepatic parenchyma. Forty days after ovulation, erythropoiesis in the hepatic parenchyma seemed established.

The immunohistochemical method revealed that almost all hemopoietic cells in the hepatic parenchyma were erythrocytic elements, being represented by large immature and small mature erythroblasts (Fig. 1). The majority part of the large immature eyrthroblasts were invaginating into the cytoplasm of hepatocytes, whereas most of the mature erythroblasts gathered in the subendothelial spaces of the sinusoids. 


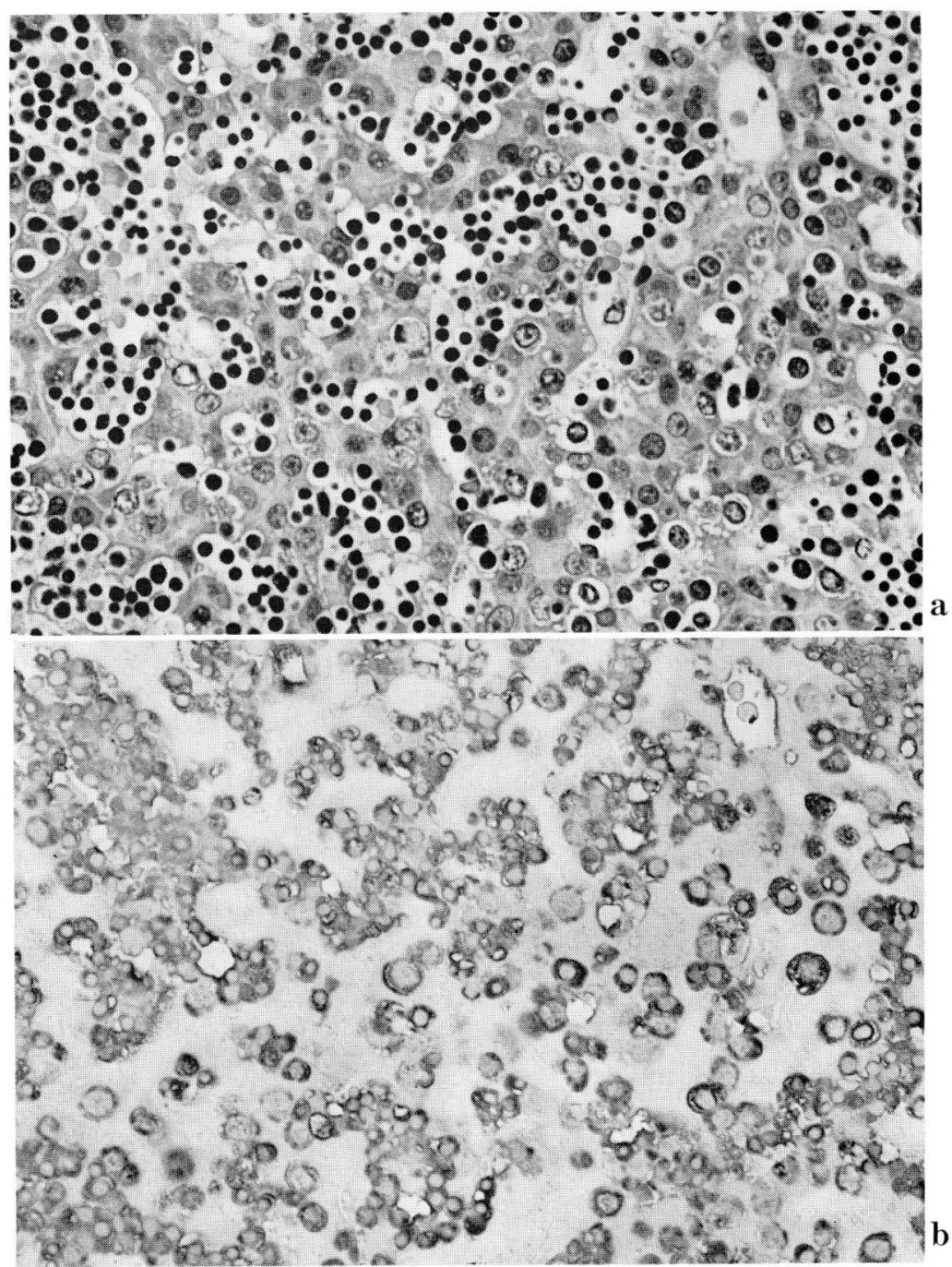

Fig. 1. Two consecutive sections of the liver of a human fetus, about 51 days after ovulation. a. Large immature erythroblasts are invaginating into the cytoplasm of hepatocytes, whereas small mature erythroblasts tend to gather in the subendothelial spaces of the sinusoids. $\times 400$. b. This section immunostained for hemoglobin $\mathrm{F}$ shows that most of the hemopoietic cells are erythrocytic. $\times 400$

II. Electron microscopic observation of hepatic hemopoiesis

All the immature hemopoietic cells in the hepatic parenchyma from 33 to 40 days after ovulation ranged in size from 13 to $15 \mu \mathrm{m}$ in diameter; the chromatin of these cells was finely dispersed in their nuclei.

A very small number of lymphoid cells with nuclei showing central and peripheral clumps of chromatin in various degrees were first found in the intercellular spaces of the hepatocytes of an embryo of $13 \mathrm{~mm}$ C. R. length (estimated age after ovulation: 40 days). These lymphoid cells quite gradually increased in number with the embryo's 
development. Erythroid progenitor cells that resembled lymphoid cells were first identified in the intercellular spaces of embryonic hepatocytes at about the tenth week of gestation.

Basophilic erythroblasts or more immature cells of the erythrocytic series were almost always invaginating into the cytoplasm of hepatocytes, and were frequently wrapped by the thin cytoplasmic rim of hepatocytes. Although hepatocytes are normally covered by numerous irregular microvilli, the surface facing the associated erythroblasts possessed few of them.

A number of desmosome-like attachments were found between the hepatocytes and the invaginated erythroblasts (Fig. 2). They were most frequently encountered between hepatocytes and basophilic erythroblasts, proerythroblasts or erythroid progenitor cells. These attachements were also noticed between hepatocytes and mesenchymal cells but were lacking between hepatocytes and hemopoietic cells of granulocytic or megakaryocytic lineages.

Mitotic figures were numerous in the basophilic erythroblasts. It was common to find a pair of late hepatic erythroid progenitor cells or proerythroblasts at the nearly same stage of maturation joined side-by-side, probably the result of mitosis in a late hepatic erythroid progenitor cell in its very early stage of differentiation (Fig. 3, 8).

\section{Ultrastructure of the erythrocytic series}

By referring to previous works (Bbessis, 1973; Fukuda, 1974; TANAKA and Goodman, 1972), the following terms concerning the erythrocytic series will be used in this paper: The adjective "early hepatic" is applied to the immature forms of the erythrocytic

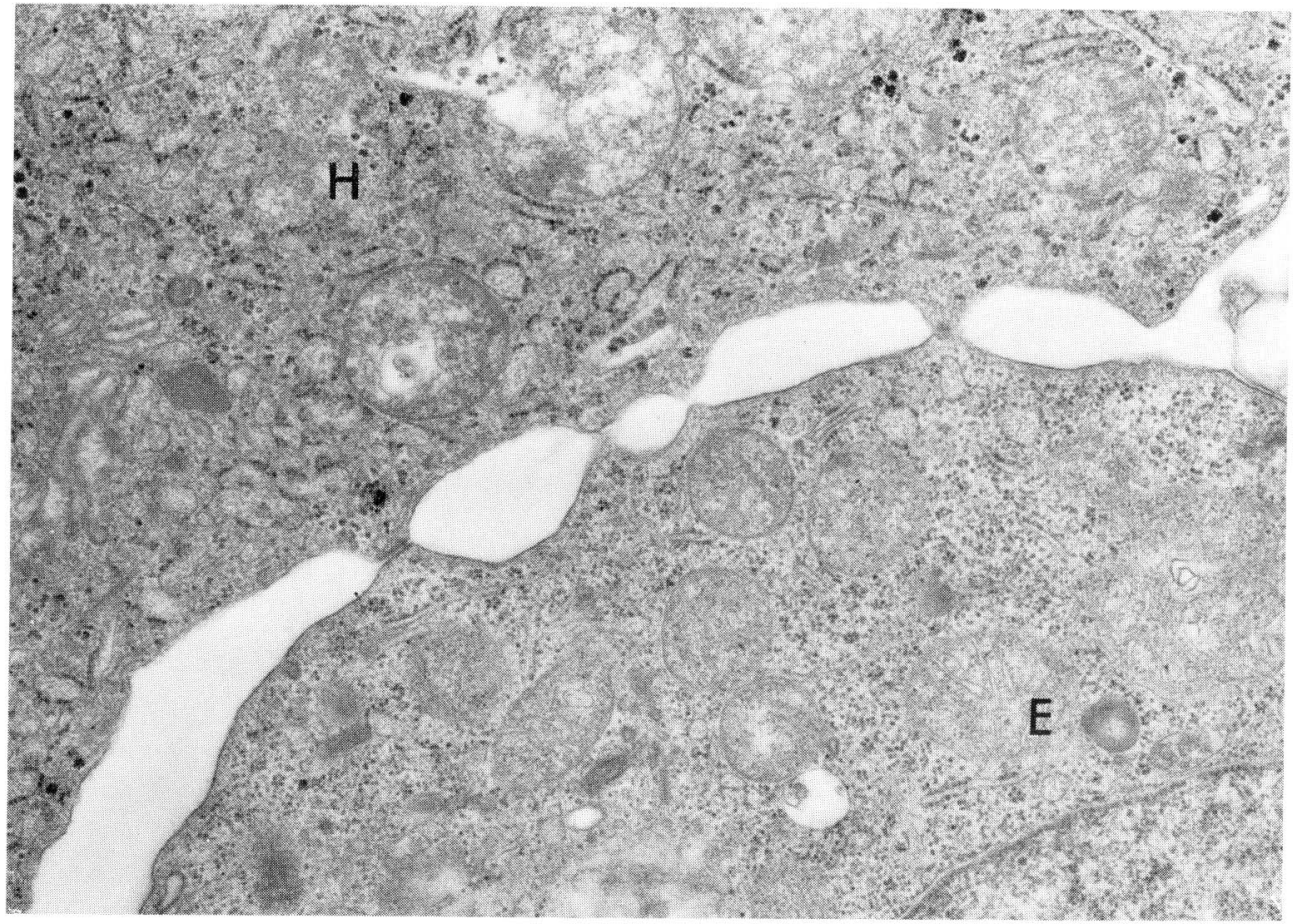

Fig. 2. Desmesome-Like attachments found between the hepatocyte $(H)$ and the invaginated erythroblasts $(E) . \quad \times 14,500$ 


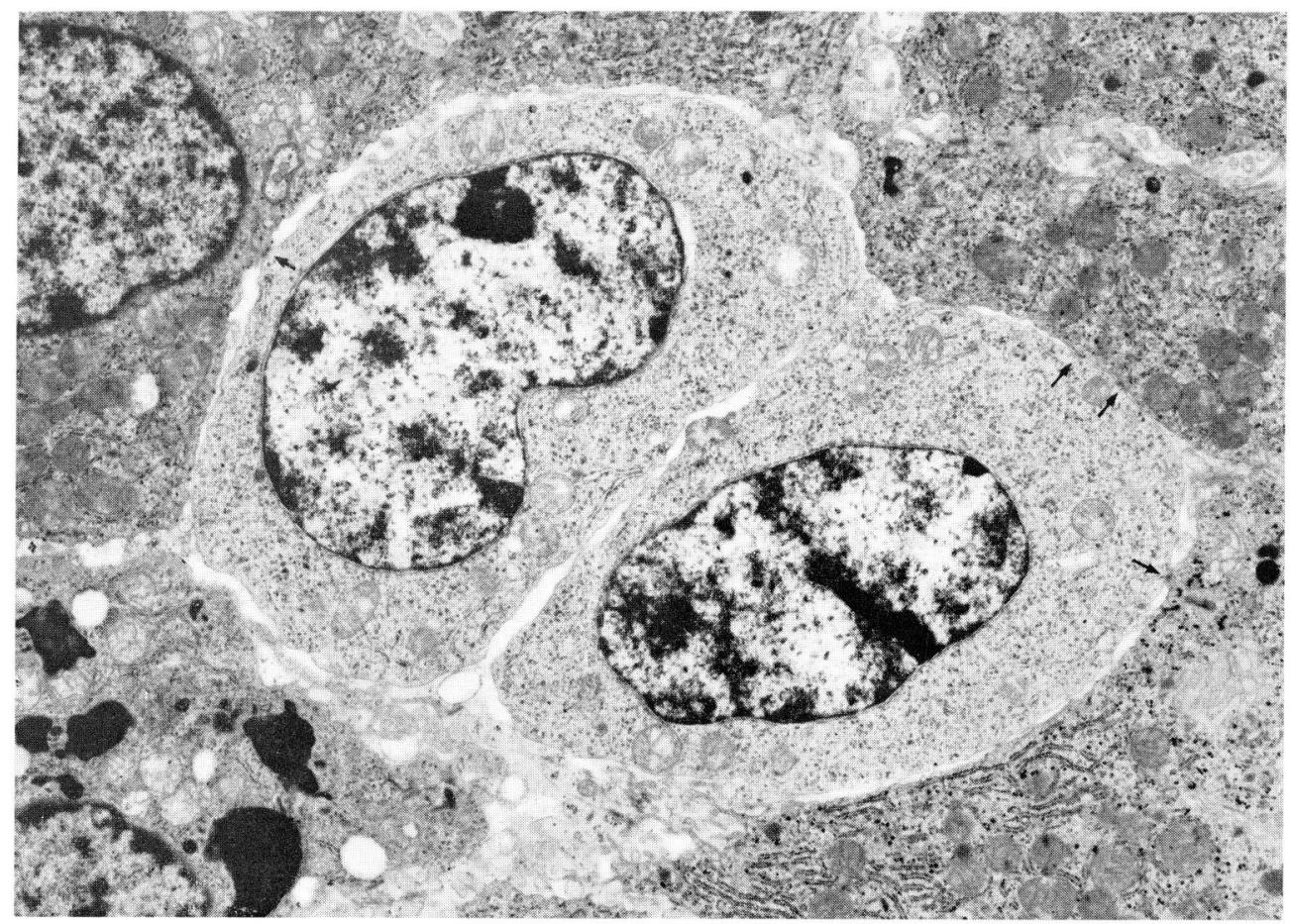

Fig. 3. Two late hepatic erythroid progenitor cells at stage II in the intercellular space of the hepatocytes of a fetus, about 11 weeks of gestation. These cells are thought to be at the same maturation stage and in the telophase of mitosis. Polyribosomes are small in number. Desmosome-like attachment (arrow). $\quad \times 7,000$

series which are observed in the liver at the early stage of hepatic hemopoiesis, and the term "late hepatic" to the immature forms of the erythrocytic series at the late stage, since the immature cells of this lineage in the liver at the early stage differ in ultrastructure from those at the late stage. However, the forms more mature than the proerythroblasts did not show any distinct morphological differences between those in the liver before and after 10 weeks of gestation. Therefore, the terms "early hepatic," "late hepatic" are applied neither to proerythroblasts nor to the more mature cells of the erythrocytic series.

\section{A. Immature cells of the early hepatic erythrocytic series}

Early hepatic erythroid progenitor cells (Fig. 4): These were round or oval in shape and ranged in size from 12 to $15 \mu \mathrm{m}$ in diameter (mean: $14 \mu \mathrm{m}$ ). The round nucleus was slightly indented and had one or two prominent nucleoli. The chromatin was finely dispersed, and the nuclear pores were numerous. The cytoplasm contained abundant polyribosomes, a few small coated vesicles, and a moderate amount of mitochondria. There were only a few short cisternae of rough endoplasmic reticulum. The Golgi apparatus was composed of a few short cisternae and small vesicles. A pair of centrioles was observed in the central area of the Golgi apparatus. 


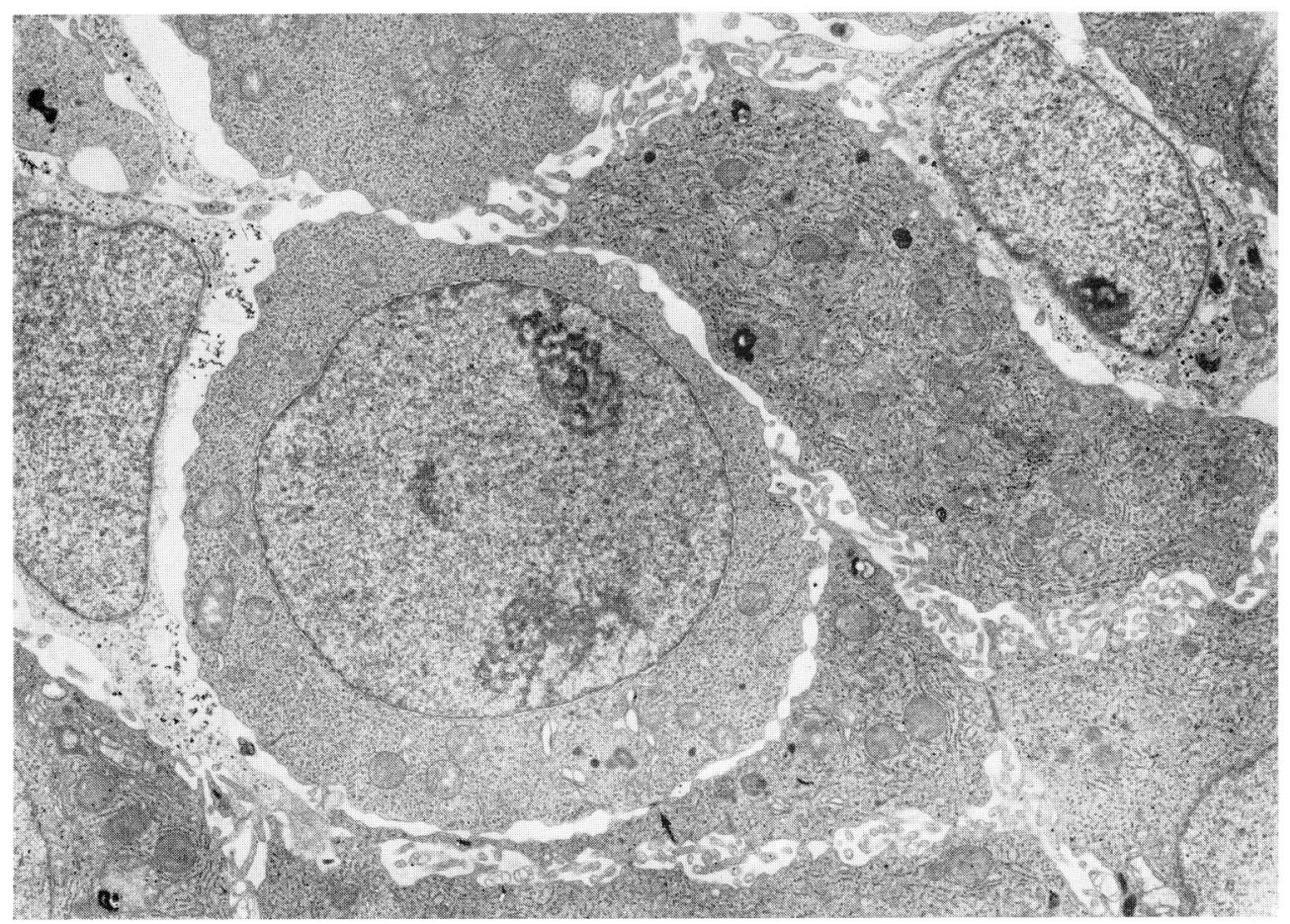

Fig. 4. An early hepatic erythroid progenitor cell in the hepatic parenchyma of an embryo, about 45 days after ovulation. Prominent nucleoli appear in the slightly indented nucleus and the chromatin is finely dispersed in the nucleus. The nuclear pores are numerous. The cytoplasm abounds in polyribosomes. The cisternae of rough endoplasmic reticulum are short and slender. Desmosome-like attachment (arrow). $\times 5,900$

\section{B. Immature cells of the late hepatic erythrocytic series}

These cells were classified into two stages; stage I and II.

1. Late hepatic erythroid progenitor cells at stage I (Fig. 5): These were round or oval, ranging from 7 to $10 \mu \mathrm{m}$ in size (mean: $8 \mu \mathrm{m}$ ). The nucleus was also rounded in shape and usually had a small nucleolus. The chromatin clumped into moderate accumulations. The nuclear pores were limited in number. The narrow cytoplasm had a small number of single ribosomes and mitochondria. Polyribosomes were only rarely found. The cisternae of rough endoplasmic reticulum were hardly found, and the small Golgi apparatus was composed of only a few cisternae and vesicles.

2. Late hepatic erythroid progenitor cells at stage II (Fig. 6): Ranging from 9 to $15 \mu \mathrm{m}$ (mean: $13 \mu \mathrm{m}$ ), these cells were oval in shape. The oval nucleus was slightly indented and possessed one or two prominent nucleoli. Chromatin was slightly to moderately gathered into reticular clumps. Polyribosomes and nuclear pores were markedly increased in number. The few cisternae of rough endoplasmic reticulum were short and slender. Mitochondria occurred in a frequency of 8 to 15 per section. The Golgi apparatus was formed of a small number of short cisternae and small vesicles. A few small granules were often found in the cytoplasm. 


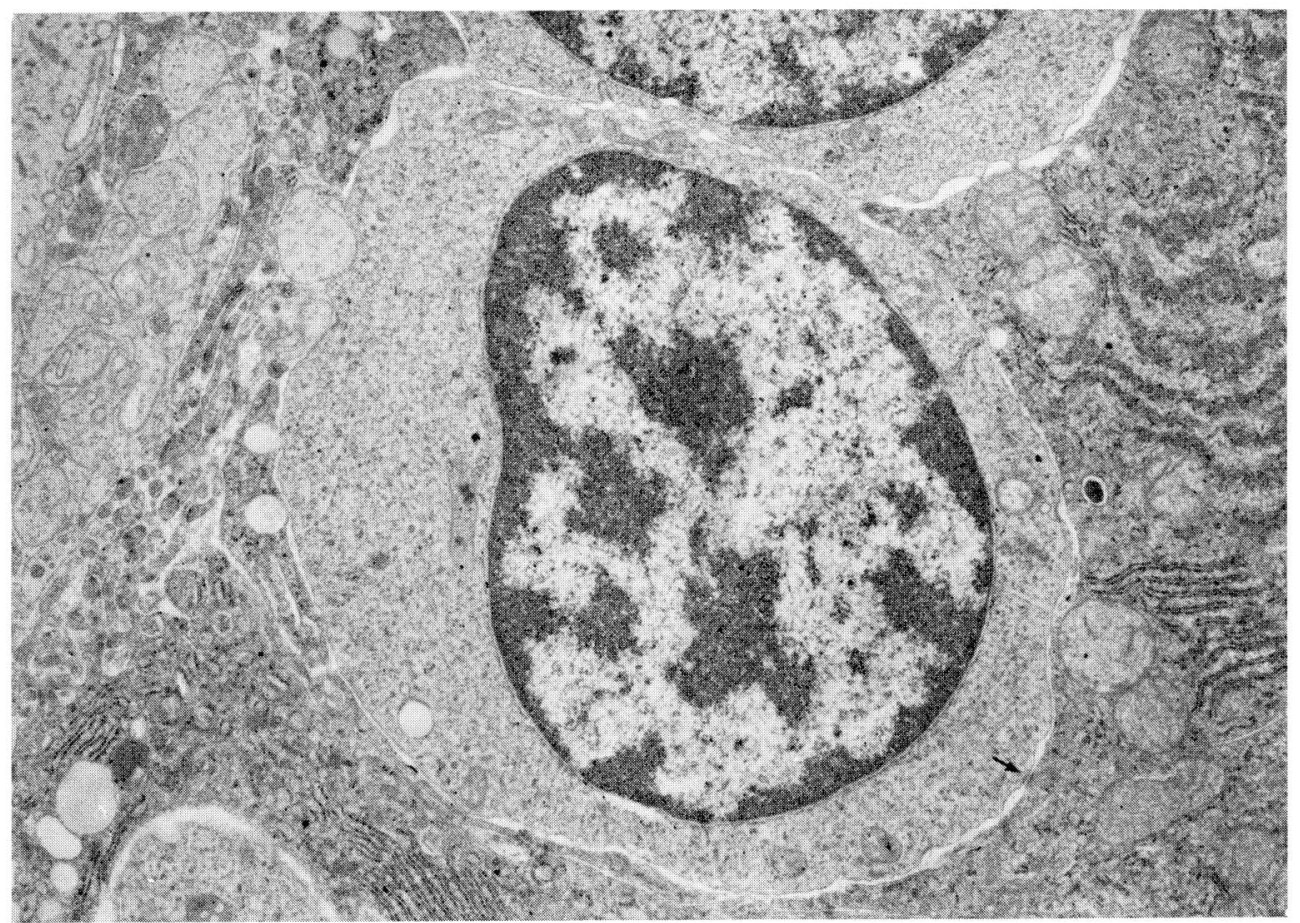

Fig. 5. Late hepatic erythroid progenitor cells at stage I in the intercellular space of the hepatocytes of a fetus at about 16 weeks of gestation. The nucleolus is not very prominent and the chromatin shows coarse clumping. The nuclear pores are small in number. Organelles are scarce in the cytoplasm. Desmosome-like attachment (arrow). $\times 10,000$

\section{Proerythroblasts and more mature erythroblasts}

1. Proerythroblasts (Fig. 7, 8): These were oval in shape and measured 12 to $16 \mu \mathrm{m}$ in diameter (mean: $14 \mu \mathrm{m}$ ). The cell shown in Figure 6 was found in the early stage of hepatic hemopoiesis and that shown in Figure 7 was observed in the late stage. In comparison with the former cell, the nucleus of the latter cell was generally irregular in contour and showed very slight reticular clumping of chromatin.

One or two nucleoli were usually found, and nuclear pores were numerous. The small Golgi apparatus was composed of several cisternae and a few small vesicles. Ten to twenty electron dense granules, up to $0.2 \mu \mathrm{m}$ in diameter, and a pair of centrioles were found between the nucleus and the Golgi apparatus. The cisternae of rough endoplasmic reticulum were slender and very small in number. Numerous polyribosomes were finely distributed. Mitochondria were 15 to 20 per section.

2. Basophilic erythroblast (Fig. 9): The round nucleus contained one or two less prominent nucleoli. The chromatin was slightly condensed along the inner aspect of the nuclear membrane. The cytoplasm was dark in appearance and packed with numerous polyribosomes and single ribosomes. The Golgi apparatus was small and cisternae of rough endoplasmic reticulum were hardly found. Mitochondria occurred in a frequency of 6 to 15 per section.

3. Polychromatic erythroblasts (Fig. 10): The nucleus consisted of area of densely aggregated granular chromatin and regions of sparse aggregation. The nucleolus 


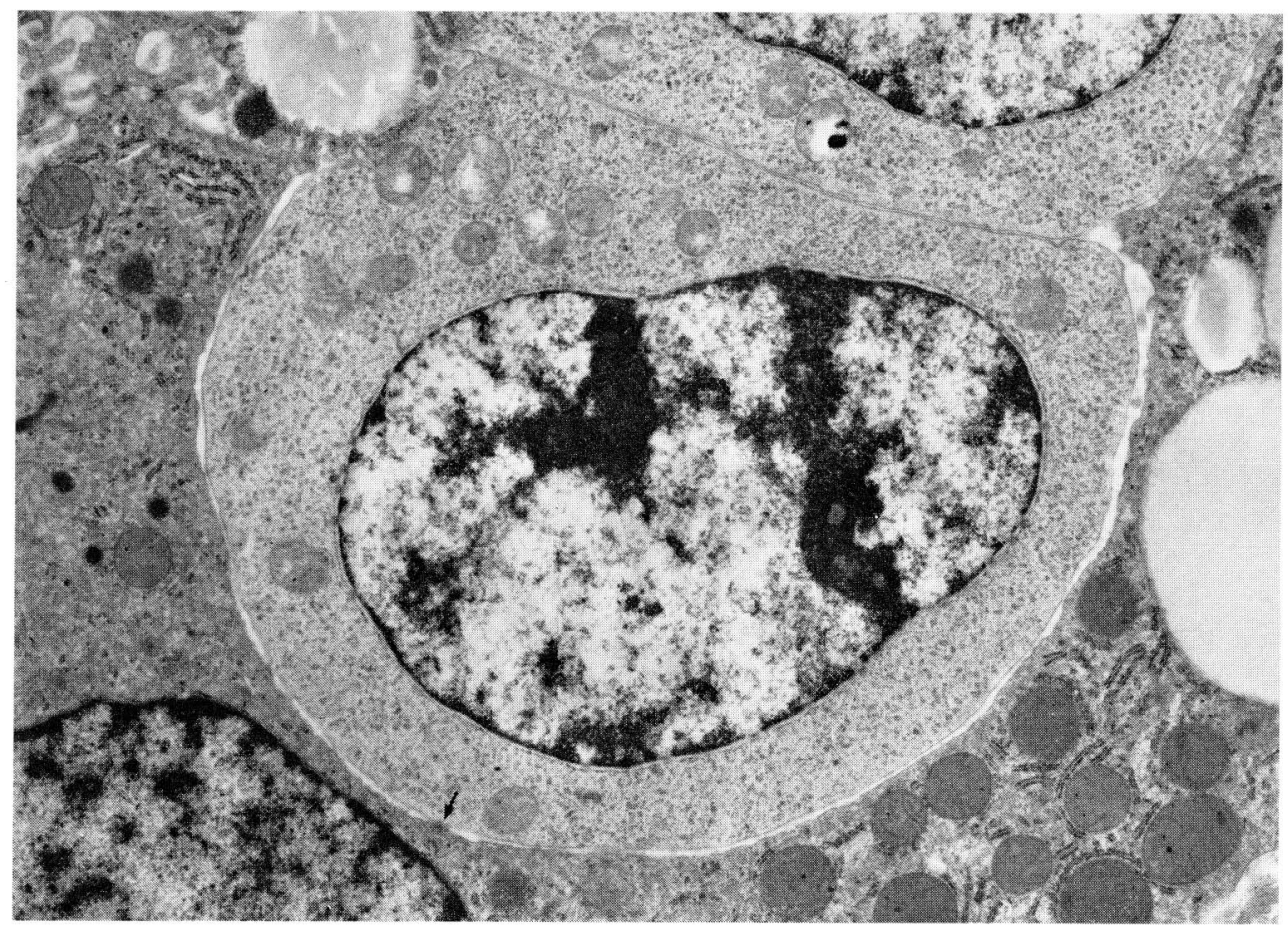

Fig. 6. Late hepatic erythroid progenitor cells at stage II in the hepatic parenchyma of a fetus, about 10 weeks after ovulation. The chromatin is dispersed in the nucleus, showing reticular clumps. The nucleolus becomes conspicuous and the nuclear pores are increased in number. Many single and polyribosomes are found in the cytoplasm. Desmosome-like attachment (arrow). $\times 93,000$

was small in size. The very dark, opaque cytoplasm contained single ribosomes and polyribosomes, a pair of centrioles, mitochondria and a small Golgi apparatus.

\section{DISCUSSION}

The ultrastructures of the differentiating cells of the human erythrocytic lineage have been studied by many investigators, all of whom believed that only one kind of hemopoietic stem cells existed in bone marrow or liver. Consequently, and the ultrastructures of erythroid cells that are more immature than proerythroblasts have been not fully understood. The present investigation reveals the existence of two types of erythrocytic series cells and the precise ultrastructure of the immature cells of two erythrocytic series in human embryonic liver.

Electron microscopic features of proerythroblasts have been described in the embryonic livers of human and experimental animals (ZAmboni, 1965; Grasso, Swift and Ackerman, 1962; Fukuda, 1974), human adult bone marrow (TANAKa and Goodman, 1972; Bessis, 1973) and the bone marrow of experimental animal (BEN-IsHAY and Yoffey, 1972). A few points of resemblance can be noted between the proerythroblasts depicted by those authors and those observed in the present study in the liver in the late stage of hepatic hemopoiesis. The first is that all proerythroblasts have a slightly 


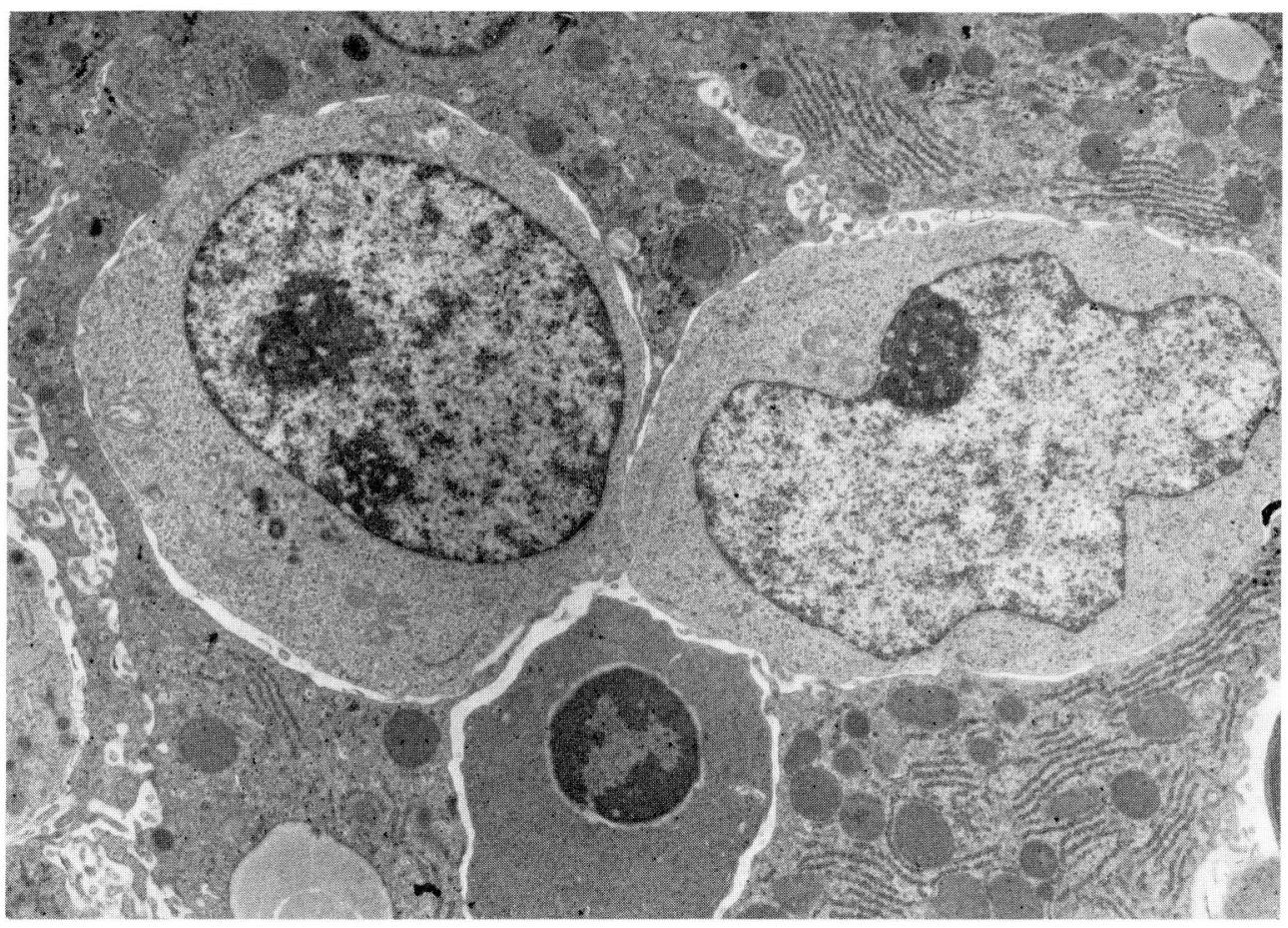

Fig. 7. A proerythroblast detected in the hepatic parenchyma of a fetus, about 8 weeks after ovulation. The chromatin is finely dispersed in the oval nucleus. Small electron-dense granules occur in the cytoplasmic area between the nucleus and the Golgi apparatus. Numerous poly ribosomes are found in the cytoplasm. $\times 6,300$

indented nucleus, and the second is that the chromatin of these cells shows very slight reticular clumping.

Proerythroblasts can readily be distinguished from the promyelocytes (TANAKA and Goodman, 1972; Fukuda, 1974; Emura, Sekiya and Ohnishi, 1983), the promonocytes (Nichols, Bainton and Farqhar, 1971; Nichols and Bainton, 1973) and the immature promegakaryocytes (Emura, Sekiya and OHnishi, 1983a) that are similar to proerythroblasts in ultrastructure by the following morphologic criteria: 1) the cisternae of rough endoplasmic reticulum of proerythroblasts are short, slender and small in number whereas the latter three cells have a large number of moderately dilated cisternae of rough endoplasmic reticulum and the perinuclear cisterna of the latter cells is also moderately dilated; 2) the Golgi apparatus of the latter cells is larger than the former; 3 ) the demarcation membrane system and a marginal zone are found in immature promegakaryocytes; 4) promonocytes contain bundle of filaments.

Desmosome-like attachments are frequently found between hepatocytes and proerythroblasts or basophilic erythroblasts. These attachments were not detected between hepatocytes and cells of the megakaryocytic (Emura, Sekiya and Ohnishi, 1983a) or granulocytic (Emura, Sekiya and Ohnishi, 1983b) lineages. Furthermore, the indirect immunohistochemical method revealed that most cells invaginating into the cytoplasm of hepatocytes were erythrocytic in nature. These findings indicate that the cells invaginating into the cytoplasm of hepatocytes or wrapped by the thin cytoplasmic rim or hepatocytes and have desmosome-like attachments to the adjacent hepatocytes are erythrocytic elements. 


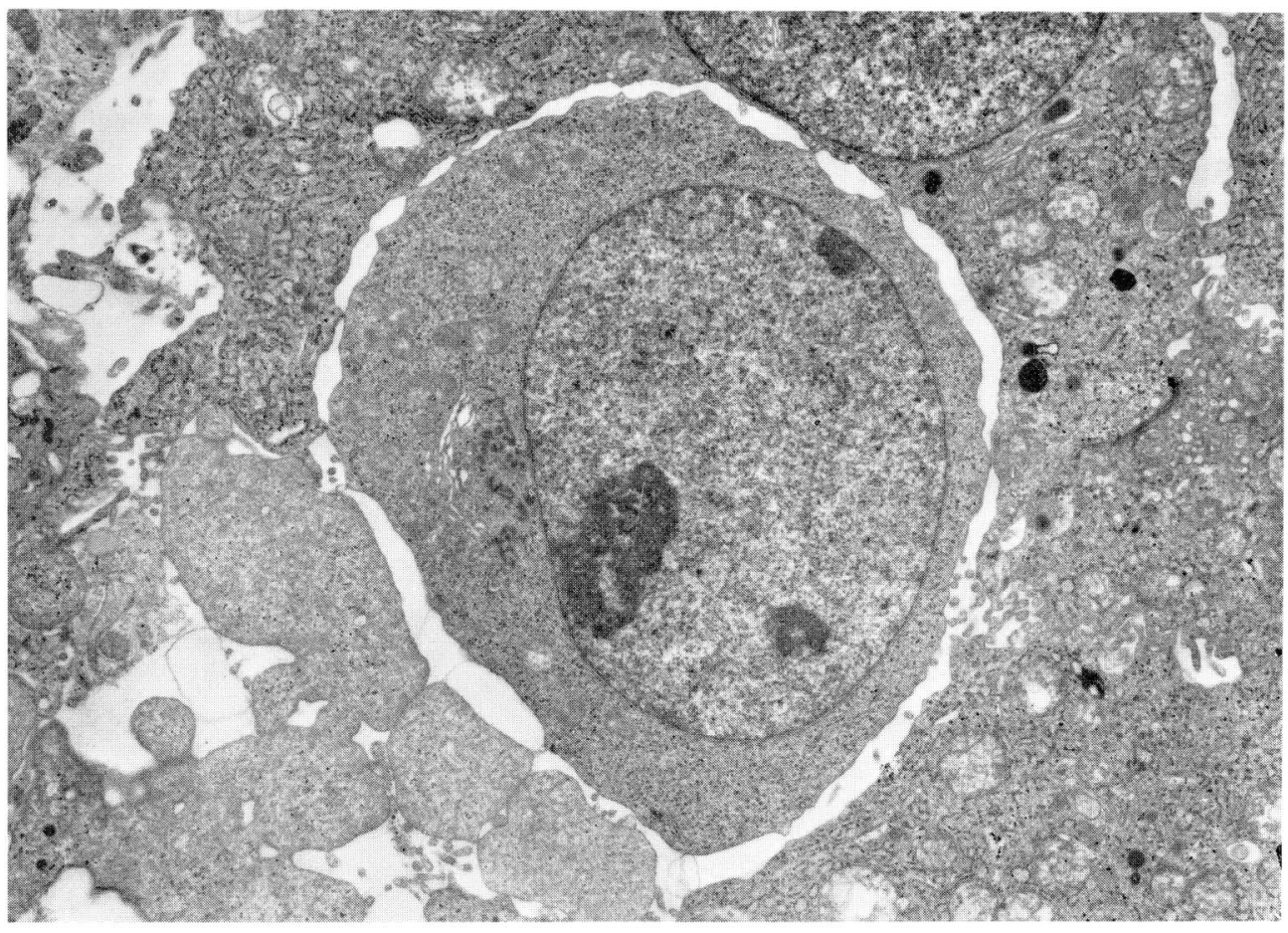

Fig. 8. Two proerythroblasts in the extravascular spaces of the liver of a fetus at about 10 weeks of gestation. In comparison with the cell shown in Figure 7, these cells are considered to be at the same maturation stage. The chromatin shows very slight clumping and the contour of the nucleus is irregular. Numerous polyribosomes and slender cisternae of rough endoplasmic reticulum are observed in the cytoplasm. $\times 6,500$

The cells in Figures 4, 5 and 6 are judged to be more immature than proerythroblast because electron dense granules that are characteristic of proerythroblasts (BEssis and Breton-Gorius, 1961; FukUda, 1974) are not formed between the Golgi apparatus and the nucleus. Concerning the early hepatic erythroid progenitor cells, the cytoplasm of proerythroblasts is darker than that of the early hepatic erythroid progenitor cells, probably the result of a production of hemoglobin. As to the late hepatic erythroid progenitor cells, since the number of polyribosomes, mitochondria and nuclear pores of the larger cell are more abundant than those of the smaller cells, the larger cell seems to be more differentiated than the smaller cell.

There are a few distinctive morphological differences between the early hepatic erythroid progenitor cells and the late hepatic ones. Firstly, the nuclear chromatin is finely dispersed in the early progenitor cells, whereas in the late progenitor cells it is gathered in moderate clumps in the center and periphery of the nucleus. Secondly, the former cells are larger in size than the late hepatic erythroid progenitor cells at stage I. Thirdly, the cytoplasmic organelles of the early hepatic erythroid progenitor cells are more abundant than those of the late hepatic erythroid progenitor cells and the nuclear pores of the former cells are more numerous than those of the latter cells. These differences were also noticed between the immature cells of the granulocytic or magakaryocytic lineages in the liver in the early stage and those in the late stage (Emura, Sekiya and Ohnishi, 1983a, b). 


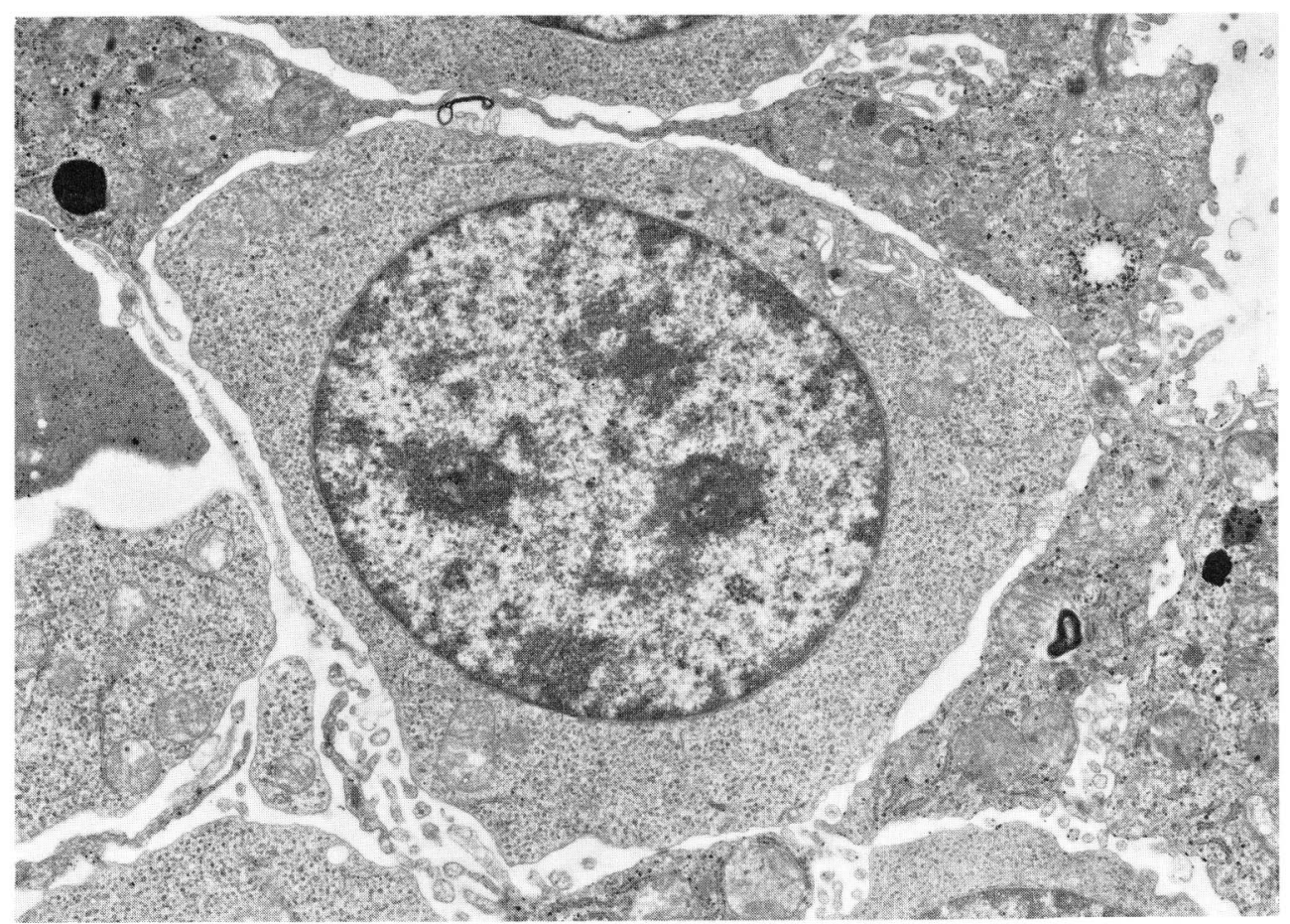

Fig. 9. A basophilic erythroblast in the hepatic parenchyma of a fetus, about 6 weeks after ovulation. This cell is wrapped by the thin cytoplasmic rim of hepatocytes. The nucleoli are less prominent and the chromatin slightly condensed along the inner aspect of the nuclear membrane. The cytoplasm is dark in appearance. $\times 8,100$

From these findings, it seems logical to draw the following three main conclusions. The first is that the hemopoietic stem cells in the liver at the late stage of hepatic hemopoiesis are small cells (about $8 \mu \mathrm{m}$ in average diameter). The chromatin of these cells shows coarse condensations and the nucleus is provided with a small nucleolus and a small number of nuclear pores. Organelles are scarce in the narrow cytoplasm. In these respects, the cells resemble small lymphocytes in ultrastructure. On the other hand, we are convinced that the hemopoietic stem cells at the early stage are large cells (about $14 \mu \mathrm{m}$ in average diameter). The nucleus has large nucleoli. The chromatin is finely dispersed and the nuclear pores are numerous. Organelles, especially polyribosomes and mitochondria, are abundant in the cytoplasm. They are not similar to small lymphocytes in ultrastructure.

The second is that the maturation courses of the cells of granulocytic, erythrocytic and megakaryocytic lineages in the liver in the early stage of hepatic hemopoiesis are different from those in the late stage, respectively. In other words, the immature committed cells of the three lineages in the early stage of hepatic hemopoiesis are surmised to be already capable of producing some specific proteins because these cells abound in polyribosomes, whereas the immature cells in the late stage are conjectured to have to pass some certain stages of maturation before they can actively synthesize their specific proteins since they have scarce polyribosomes and rough endoplasmic reticulum.

The third is that the immature cells of the three lineages at the early stage resem- 


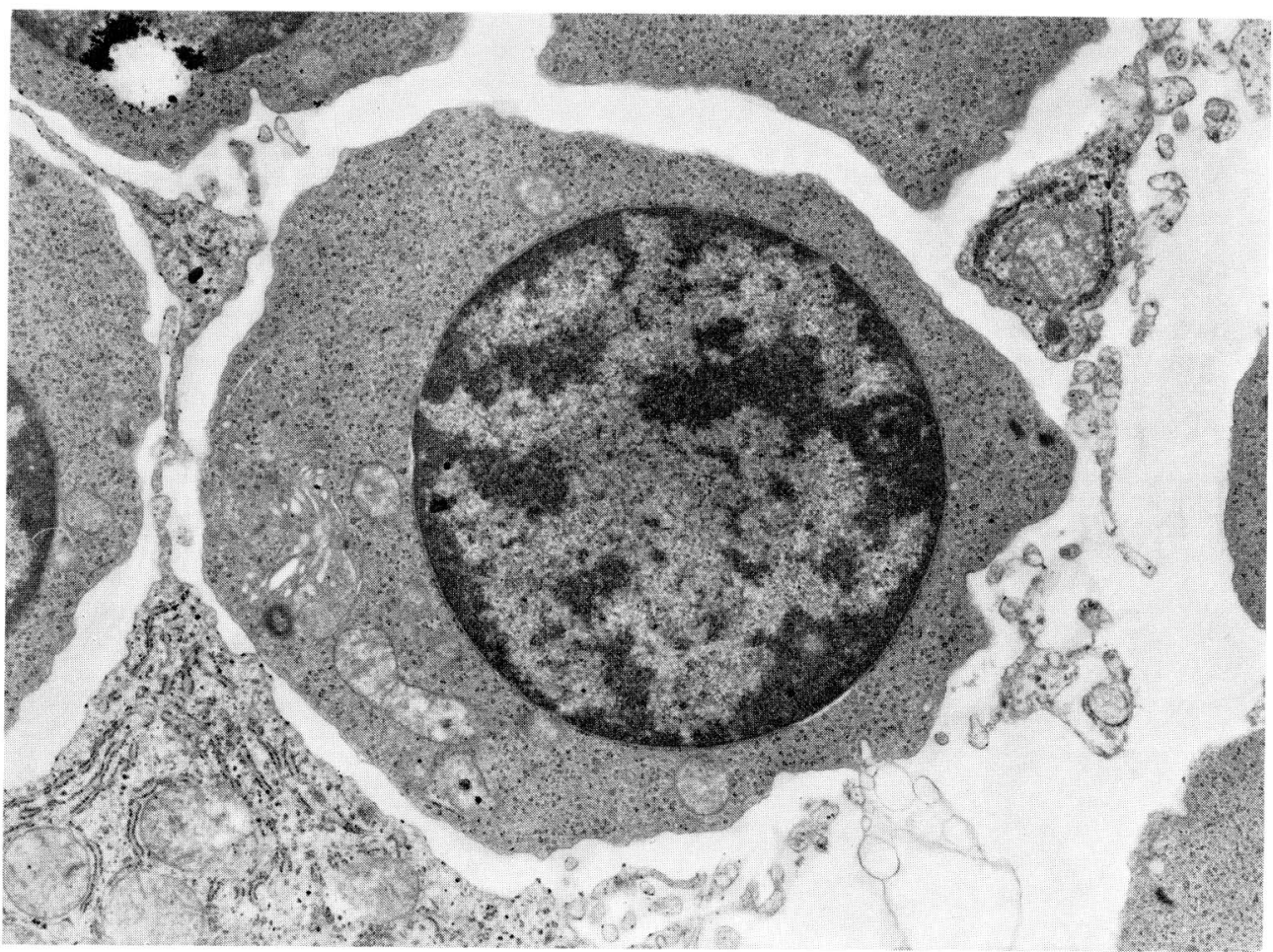

Fig. 10. A polychromatic erythroblast in the hepatic parenchyma of a fetus, about 8 weeks after ovulation. $\times 12,000$

ble each other and, in the same way, those at the late stage are similar to one another, but they are erythrocytic, granulocytic or megakaryocytic in nature even when they resemble small lymphocytes.

Acknowledgments. Appreciation is expressed to the doctors of obstetrics and gynecology at Takeyama Hospital and Saiseikai Niigata Hospital for providing cases. Appreciation is also exressed to Mr. T. Hasegawa, Mr. K. Sato and Mr. S. Momozaki, Department of Pathology, School of Medicine, Niigata University for their technical assistance.

\section{REFERENCES}

Becker, A. J., E. A. McCulloch and J. E. Till: Cytological demonstration of the clonal nature of spleen colonies derived from transplanted mouse marrow cells. Nature 197: 452-454 (1963).

Bekkum, D. W., M. J. Van Noord, B. Van Maat and K. A. Dicke: Attempts at identification of hemopoietic stem cells in mouse. Blood 38: 547-558 (1971).

Ben-Ishay, Z. and J. M. Yoffey: Ultrastructural studies of erythroblastic islands of rat bone marrow. II. The resumption of erythropoiesis in erythropoietically depressed rebound marrow. Lab. Invest. 26: 637-647 (1972).

Bessis, M. (ed.): Living blood cells and thier ultrastructure. Springer-Verlag, Berlin-HeidelbergNew York, 1973.

Bessis, M. and J. Breton-Gorius: Ultra-structure du pro-erythroblasts. Nouv. Rev. franç. Hemat. $1: 529-533^{*}(1961)$. 
Dicke, K. A., M. J. Van Noord and D. W. Van Bekkum : Attempts at morphological identification of hemopoietic stem cell in rodents and primates. Exp. Hematol. 1: 36-45 (1973).

Emura, I., M. Sekiya and Y. Ohnishi : Two types of immature magakaryocytic series in the human fetal liver. Arch. histol. jap. 46: 103-114 (1983a). embryonic liver. Arch. histol. jap. 46: 229-242 (1683b).

Fauser, A. A. and A. H. Messner: Granuloerythropoietic colonies in human bone marrow, peripheral blood and cord blood. Blood 52: 1243-1248 (1978).

: Identification of magakaryocytes, macrophages and eonsiophiles in colonies of human bone marrow containing neutrophilic granulocytes and erythroblasts. Blood 53: 1023-1027 (1979).

Fukuda, T.: Fetal hemopoiesis. II. Electron microscopic studies on human hepatic hemopoiesis. Virchows Arch. B Cell Pathol. 16: 249-270 (1974).

Grasso, J. A., H. Swift and A. G. Ackerman : Observations on the development of erythrocytes in mammalian fetal liver. J. Cell Biol. 14: 235-254 (1962).

Nichols, B. A. and D. F. Bainton: Differentiation of human monocytes in bone marrow and blood: Sequential formation of two granule populations. Lab. Invest. 29: 27-40 (1973).

Nichols, B. A., D. F. Bainton and M. G. Farquhar : Differentiation of monocytes: Origin, nature, and fate of their azurophil granules. J. Cell. Biol. 50: 498-515 (1971).

Tanaka, Y. and J. R. Goodman: Electron microscopy of human blood cells. Harper \& Row, New York-Evanston-San Francisco-London, 1972.

Till, J. E. and E. A. MuCulloch: A direct measurement of the radiation sensitivity of normal mouse bone marrow cells. Rad. Res. 14: 313-322 (1961).

Zamboni, L.: Electron microscopic studies of blood embryogenesis in humans. I. Ultrastructure of the fetal liver, II. The hemopoietic activity in the fetal liver. J. Ultrastr. Res. 12: 509-524, 525-541 (1965).

\author{
江 村 巖 \\ 厂951 新潟市旭町通 1 \\ 新潟大学医学部 \\ 第二病理学教室
}

Dr. Iwao Emura

2nd Department of Pathology

Niigata University School of Medicine

1 Asahimachi-dori, Niigata

951 Japan 